\title{
Abstract \\ Income and Multidimensional Poverty of Children in Croatia
}

\author{
RESEARCH ARTICLE
}

\section{Marko Ledić*}

\begin{abstract}
Although there are numerous studies dealing with poverty and the problems it generates, this topic is not adequately represented in Croatian literature. In this paper, we examine income and multidimensional poverty of children in Croatia in the period from 2010 to 2014. In addition, we compare indicators of child poverty in Croatia with other European countries based on EU-SILC data. In the first part of the study, we focus only on the analysis of income poverty of children, which means that we assume that children's welfare is determined by their equivalent income. As there is an increasing number of studies that have recognized the multidimensional concept of well-being, in the second part of the paper we use the Alkire-Foster methodology, which allows us to measure multidimensional poverty taking into account the broader definition of human well-being. Our multidimensional poverty measure includes the dimensions of income, quality of housing, material deprivation and deprivation associated with the necessary life needs (basic deprivation). Our results show that the relative poverty rate of children increased from 2010 to 2012, but from 2012 to 2014 it decreased. Based on 2014 results, we can conclude that Croatia belongs to a group of countries with higher relative poverty rates of children. Although in Croatia the poverty rates of children who have been in poverty for only one year are equal to the European average, Croatia nevertheless belongs to the group of countries with the highest rates of poverty for children who have spent four years in poverty. As was the case with income poverty, the rate of multidimensional poverty of children in Croatia increased from 2010 to 2012, but then the rate decreased by 2014 . According to the indicators of multidimensional poverty in 2014 , Croatia belongs to a group of countries with a higher percentage of poor children.
\end{abstract}

Keywords: child poverty, income poverty, multidimensional poverty, poverty measurement, Alkire-Foster method, EU-SILC, Croatia

JEL classification: I30, I32, J13, D63

\footnotetext{
* Marko Ledić, assistant, Faculty of Economics and Business, University of Zagreb, e-mail:mledic@efzg.hr.
} 